\title{
Stigma: a linguistic analysis of the UK red-top tabloids press's representation of schizophrenia.
}

\begin{abstract}
Aims.

Media representations of mental health problems may influence readers' understanding of, and attitude towards, people who have received psychiatric diagnoses. Negative beliefs and attitudes may then lead to discriminatory behaviour, which is understood as stigma. This study explored the language used in popular national newspapers when writing about schizophrenia and considered how this may have contributed to the processes of stigmatisation towards people with this diagnosis.

\section{Methods.}

Using corpus linguistic methods, a sample of newspaper articles over a 24 month period that mentioned the word 'schizophrenia' was compared with a similar sample of articles about diabetes. This enabled a theory-driven exploration of linguistic characteristics to explore stigmatising messages, whilst supported by statistical tests (Log-Likelihood) to compare the data sets and identify words with a high relative frequency.
\end{abstract}

Results.

Analysis of the 'schizophrenia' data set identified that overtly stigmatising language (e.g. "schizo") was relatively infrequent, but that there was frequent use of linguistic signatures of violence. Articles frequently used graphic language referring to: acts of violence, descriptions of violent acts, implements used in violence, identity labels and exemplars of well-known individuals who had committed violent acts. The word 'schizophrenic' was used with a high frequency $(n=108)$ and most commonly to name individuals who had committed acts of violence.

\section{Discussion.}

The study suggests that whilst the press have largely avoided the use of words that press guidance has steered them away from (e.g. "schizo" and "psycho") that they still use a range of graphic language to present people with a diagnosis of schizophrenia as frighteningly 
'other' and as prone to violence. This repetition of negative stereotypical messages may well contribute to the processes of stigmatisation many people who experience psychosis have to contend.

\section{Introduction.}

Many people who receive a psychiatric diagnosis experience reduced life opportunities as a result of prejudice and discrimination. ${ }^{1}$ These include opportunities for work ${ }^{2}$, housing ${ }^{3}$, access to financial resources ${ }^{4}$ and optimal healthcare. ${ }^{5}$ Some people find that the diagnosis leads to distancing behaviours from friends and family ${ }^{6}$, which in turn can make it harder to manage the challenges life presents. Realistic fears of prejudice and discrimination can also prevent people seeking support when they experience distress ${ }^{7}$. All of this has been implicated in the pattern of reduced life expectancy for people with a diagnosis of schizophrenia. ${ }^{8,9}$

In the context of mental health care, prejudice and discrimination are often referred to as 'stigma'. This term has been criticised for individualising and medicalising the issue and at times ignoring issues of power and oppression. ${ }^{10,11}$ However the term is widely used in the literature that we review here. As such, stigma is understood to include the processes of labelling human differences ${ }^{12}$, of negative stereotypes being applied to understand groups of people ${ }^{12}$, who as a result are experienced as different from "us"12 and typically this is linked with negative affective responses. ${ }^{14}$ It also refers to behaviours that lead to discrimination and loss of life opportunities, such as those noted above, which require the exercise of power to be enacted. ${ }^{15}$

Stereotypes play an important role in the process of stigmatisation and there is evidence that the press' representation of mental health may contribute to negative attitudes in the readers. Research has demonstrated that reading news stories about violence committed by someone identified as having a diagnosis of a mental illness is associated with increased negative attitudes towards all people with such diagnoses. ${ }^{16,17,18}$ Whilst these studies are only able to identify an immediate effect, rather than a lasting influence, they lend support to the view that the press representations do influence the beliefs and attitudes of their readers. 
Stigma may also become internalised by those who receive a diagnosis. This is referred to as self-stigma ${ }^{1}$ and this is associated with lowered self-esteem and self-efficacy ${ }^{13}$. Media stereotypes appear to have a direct effect in this area as well. Campaigner Jonny Benjamin, for example, described the desolation he experienced on receiving the diagnosis of schizophrenia: "All I knew was what I read in the papers, that people with schizophrenia are violent and incapable of recovery". ${ }^{19}$

In order to try and improve coverage, guidance has been published for the media in general ${ }^{20}$ and specifically for the press. ${ }^{21}$ These have been supported by awards for practices that promote anti-stigmatising beliefs and attitudes ${ }^{22}$ and by training for people working in the media. ${ }^{23}$ Language choice is understood to play an important part in the influence of the media on publics understanding of mental health problems, , evoking negative emotional responses such as fear, and potentially constructing spoilt identities. ${ }^{24}$

Research into how the press have written about mental health has highlighted a pattern of using pejorative language. ${ }^{25,26}$ This has included the use of words such as monster and lunatic ${ }^{27}$, maniac and $p s c y h o^{28}$, deranged and $\operatorname{schizo}^{29}$ and broadly sensationalistic language. ${ }^{30}$ In the UK, the red-top tabloid press has been found to use this type of language more commonly than other sectors of the press ${ }^{31,32}$ and consequently this has raised concern about how this group of newspapers write about mental health, particularly given their high readership. ${ }^{33}$ Collectively, this type of language is understood to contribute to readers constructing understandings about people with mental health problems as other, and a potential threat. ${ }^{34}$

In their seminal paper about the processes of stigmatisation, Link and Phelan ${ }^{15}$ comment that the degree to which a label shapes identities of the individuals within the group, is reflected in language that refers to individuals simply by their diagnosis. This line of thought has prompted enquiry into how the word 'schizophrenic' has been used in the press to name an individual, which Clement and Foster ${ }^{31}$ refer to as using the word as an 'equator descriptor'. Findings in the UK suggest that it has been common across all press outputs, but particularly common in articles describing violent acts. ${ }^{31}$ 
This study explored the linguistic characteristics of the red-top tabloids' representation of 'schizophrenia'. The research question was: how may the linguistic characteristics of the redtop tabloids' representation of schizophrenia contribute to the processes of stigmatisation?

\section{Method.}

The use of sensationalist language and equator descriptors in UK red-top tabloid newspapers were explored using corpus linguistic methods. Corpus linguistics is a common approach within linguistic analysis ${ }^{35}$ but is underutilised in mental health research. Research into the language used to describe mental health problems has typically relied on a priori decisions about which words to identify and count within the data set. Corpus linguistic software uses an inductive approach to explore linguistic patterns without prior assumptions and more efficiently than would be possible by hand ${ }^{36}$. This study used the computer software, AntConc ${ }^{37}$ to support the analysis as this has been found to be reliable ${ }^{38}$ and is free to download.

Two types of analysis are commonly used in corpus linguistics. The first is concordance analysis in which each line of text is presented that contains a particular word, selected by the researcher. This is referred to as the key word in context ${ }^{39}$, and enables an efficient scanning of word usage. ${ }^{40}$ Each example can be explored further if the meaning is unclear from the one line. The second type of analysis is keyness analysis where the data set under enquiry is compared with a comparator data set in order to identify words that are used with greater or less proportional frequency. ${ }^{41}$ Statistical analysis is used to establish the likelihood that such a difference would occur by chance. The words are rank ordered by their statistical value and the researcher then makes theoretically informed decisions about which words characterise the data set under review. In this research, for example, the theoretical concept of stigma drove the decision about the identification of words that may contribute to stigmatising beliefs and attitudes.

The data set of newspaper articles was constructed using the LexisNexis database, which is the industry standard for newspaper research in the UK and US. ${ }^{41}$ The database allows for a search of articles within all the UK red-top tabloid newspapers (The Sun, The Daily Mirror, The Star, The People, The Sunday Sun, The Mirror on Sunday, The Star on Sunday), filtered by all 
articles containing a key word, and by a chosen time period. For this study all articles within this group of papers that used either the word schizophrenia or schizophrenic were identified throughout a 24 month time period from 01.04.16 to 31.03.18. All of these articles were copied into a Word document and half were randomly selected creating a data set of 210 articles for analysis. To support the keyness analysis, a data set was constructed of articles within the same group of newspapers and during the same time period, but filtered by the inclusion of the words diabetes or diabetic. This comparator data set was constructed as it would share the same qualities of time period and newspapers and would only be differentiated by the difference of a physical health rather than psychiatric diagnosis. Diabetes was chosen as it had proven to be a relevant comparator diagnosis in previous research into press representations of mental illness. ${ }^{42}$

The Log-Likelihood test was used to identify words with a proportionally high frequency in the 'schizophrenia' dataset compared against the diabetes dataset. Log-Likelihood is more conservative than alternative statistical tests, such as Chi-Squared, when analysing whether words with low frequency are used proportionally more frequently in one dataset than the other, beyond the differences expected by chance. ${ }^{41}$ Words with a statistical value greater than 3.84 are regarded as regarded as having a significant proportional high frequency of use, based on an alpha threshold of $\mathrm{P}<0.05 .{ }^{43}$ All words in the 'schizophrenia' dataset with a statistical value greater than 3.84 were scanned to identify linguistic features that may contribute to stigmatising messages and words that were regarded as stigmatising in press guidance were additionally sought.

\section{Results.}

Stigmatising descriptors.

From the list of words with a statistical value greater than $3.84,44$ words were identified as contributing to stigmatising constructions of schizophrenia and an additional 4 words were identified that were contrary to press guidance (schizo, psycho, psychos, beast). The striking characteristic of the 'schizophrenia' data set was the number of violence-related words 
present, a typical example was: "The schizophrenic slashed five others before cops Tazered him". ${ }^{44}$ The words fell into five categories: acts of violence (e.g. murder), descriptions of acts (e.g. violent), implements of violence (e.g. hammer), identity labels (e.g. schizophrenic) and exemplars (e.g. Sutcliffe). The findings illustrate the repeated use of graphic language in this group of newspapers over a 24 month period in relation to people with a diagnosis of schizophrenia. Table 1 shows both the frequency with which the words were used and their proportional frequency in the 'schizophrenia' than in the 'diabetes' data set, by means of the Log-Likelihood value $\left(G_{2}\right)$. The exemplars identified are culturally specific references to individuals who have notoriety in the UK and have committed homicide, these are included as they are regarded as a mechanism within the press to heighten the affective response of fear in readers. ${ }^{28}$

Table 1. Linguistic signatures of violence in 'schizophrenia' articles, arranged by categories and ranked by Log-Likelihood value $\left(G_{2}\right)$.

\begin{tabular}{|c|c|c|c|c|c|c|c|c|c|c|c|c|c|c|}
\hline \multicolumn{3}{|c|}{ Acts of violence. } & \multicolumn{3}{|c|}{ Description of acts. } & \multicolumn{3}{|c|}{ Implements of violence. } & \multicolumn{3}{|c|}{ Identity labels. } & \multicolumn{3}{|c|}{ Exemplars. } \\
\hline Freq. & $G 2$ & Word & Freq. & $G 2$ & Word & Freq. & $G 2$ & Word & Freq. & $G 2$ & Word & Freq. & $G 2$ & Word \\
\hline 74 & 92.81 & murder & 17 & 15.13 & violent & 17 & 15.13 & hammer & 105 & 129.19 & schizophrenic & 153 & 191.91 & Sutcliffe \\
\hline 59 & 74.00 & stabbed & 14 & 11.74 & horror & 7 & 8.78 & screwdriver & 88 & 74.92 & killer & 128 & 160.55 & Brady \\
\hline 65 & 49.57 & killed & 9 & 11.29 & brutal & 11 & 8.44 & axe & 12 & 15.05 & attacker & 63 & 79.02 & Hindley \\
\hline 38 & 47.66 & murders & 13 & 10.63 & horrific & 5 & 6.27 & gun & 11 & 13.80 & killers & 28 & 35.12 & Huntley \\
\hline 30 & 37.63 & attacked & 7 & 8.78 & chilling & 4 & 5.02 & knives & 18 & 12.63 & monster & 11 & 13.80 & Erskine \\
\hline 105 & 28.98 & death & 6 & 7.53 & crazed & & & & 10 & 7.37 & murderer & 5 & 6.27 & Bamber \\
\hline 22 & 27.60 & killings & 6 & 7.53 & frenzied & & & & 4 & 5.02 & murderers & 5 & 6.27 & Shipman \\
\hline 11 & 13.80 & knifed & 4 & 5.02 & gruesome & & & & 4 & 5.02 & rapist & 4 & 5.02 & Breivik \\
\hline 10 & 12.54 & strangled & & & & & & & 1 & 1.25 & psychos & & & \\
\hline 5 & 6.27 & axed & & & & & & & 1 & 1.25 & schizo & & & \\
\hline 5 & 6.27 & bludgeoned & & & & & & & 4 & 0.43 & beast & & & \\
\hline 5 & 6.27 & hacked & & & & & & & 2 & 0.22 & psycho & & & \\
\hline 4 & 5.02 & beheading & & & & & & & & & & & & \\
\hline 4 & 5.02 & raped & & & & & & & & & & & & \\
\hline 7 & 4.28 & slashed & & & & & & & & & & & & \\
\hline
\end{tabular}

\section{'Schizophrenic' as an equator descriptor.}

The word schizophrenic is sometimes used as a short-hand for referring to people with a diagnosis of schizophrenia. Press guidance advises against using this term, suggesting it encourages readers to reduce the identity of individuals to a diagnostic label ${ }^{15,21}$. Concordance analysis of the 'schizophrenia' data set identified that the word schizophrenic was used 105 times. The word was present in 101 articles, indicating that in $48 \%$ of the 
articles in the dataset the word 'schizophrenic' was used, and closer analysis identified its use fell into five discrete categories, represented in Table 2.

Table 2. The categories and frequencies of use of the word 'schizophrenic'.

\begin{tabular}{|l|c|c|c|c|c|}
\hline & $\begin{array}{c}\text { Formal } \\
\text { (violence) }\end{array}$ & $\begin{array}{c}\text { Formal } \\
\text { (not violence) }\end{array}$ & Fictional. & Informal. & Metaphorical. \\
\hline $\begin{array}{l}\text { No. of } \\
\text { instances. }\end{array}$ & 58 & 22 & 5 & 13 & 7 \\
\hline
\end{tabular}

There were 80 references to people with a formal diagnosis of schizophrenia. In the light of the findings reported above, these examples were separated into those that were linked to violence and those that were not, indicating that 58 instances related to violence and 22 not to violence. There were five references to fictional characters in films, books or television. There is evidence of over-representation of mental health in fictionalised accounts of violence, such as horror movies ${ }^{45}$, which is a source of concern about the broader cultural representation of mental health. However, these references to fictional characters were counted separately as it is understood that in the context of press outputs readers would treat them differently from accounts relating to real people. ${ }^{46}$ There were 13 instances of what we termed 'informal' usage, i.e. where it is clear that the term does not refer to an 'official' or formal diagnosis. The most common news story referred to the US President Donald Trump's former Communications Officer Anthony Scaramucci. One typical example, from the Daily Mirror", stated: "Kelly takes over his position from Reince Priebus who was sacked 24 hours after communications head Anthony Scaramucci branded him a "f*****g paranoid schizophrenic"." Finally, there were seven instances of 'metaphorical' use of the term schizophrenic to denote things or people being split or contradictory, examples included: "Jurgen Klopp's schizophrenic side" 48 . Here, the tone was not strongly negative with regard to implications of violence, but usually presented the state of affairs as leading to negative consequences.

\section{Discussion.}


The striking feature of the study findings is the repetition and graphic nature of the language of violence used in the 'schizophrenia' data set. To state simply that the articles were characterised by graphic language misses the impact of the use of such emotive words. The repetition of people being 'stabbed', 'strangled', and 'beheaded' with a 'hammer', 'screwdriver' or 'axe' are designed to induce a response of fear in readers. ${ }^{21}$ These affective responses are central to people developing prejudicial attitudes, as stereotypical beliefs about dangerousness become fused with emotional reactions to those beliefs. ${ }^{14}$ In this context the newspapers appear to use, almost casually, language that reduces a person's identity to one dominated by the act of violence, e.g. 'killer' or 'monster'.

The drive for the press to avoid the use of the word 'schizophrenic' as an equator descriptor appears to have had little effect: in our sample it was frequently used ( $n=105)$, particularly in relation to people who have committed acts of violence $(n=58)$. The review of the use of the word 'schizophrenic' indicated that it was used almost three times more often in relation to real people who had committed acts of violence than those who had not. Whilst the interpretation of a text will vary from individual to individual, influenced by their own life experiences and social context ${ }^{49}$. The results suggests that when the language in articles encouraged the reader to view the person as 'other', for example due to their 'crazed' violence it was more likely also to reduce the identity of the person to their diagnosis, (i.e. by referring to individuals as 'schizophrenics)'. This reduction of someone to a diagnosis, combined with linking that diagnosis with violence, is likely to reinforce the process of 'othering' whereby readers come to see certain people as insurmountably different and abnormal. ${ }^{34}$ This may be particularly significant as establishing empathetic links with people with a diagnosis of mental illness is important in countering negative attitudes and beliefs. ${ }^{50}$

Previous research in this field has tended to focus on the identification of pre-established lists of words that are considered to be stigmatising, such as $p s y c h o^{28}$, and schizo. ${ }^{29}$ Such words were used relatively infrequently. On the one hand this could be seen as evidence of a positive move within the press industry, and perhaps that campaigns to encourage journalists to avoid these terms have had some effect. However, by broadening the focus beyond these pre-determined words to analyse the characteristics of the data set, the present study has revealed a pattern of linguistic signatures of violence in the articles. Link and Phelan ${ }^{15}$ caution that the pervasive nature of stigmatisation means that attempts to address one discrete area 
may well mean that alternative methods of stigmatisation are employed. The findings from this study support that view and raise concerns that whilst the press may respond positively to a checklist of terms to avoid, it continues to draw on language that constructs people with a diagnosis of schizophrenia as violent.

The use of corpus linguistics has proven to be a useful method to analysis beyond a priori lists of words that the press should avoid, or use with caution, to a wider survey of the language used in constructions of identities. The findings are consistent with those from other types of research in the field about the repetition of themes of violence in mental health news ${ }^{51}$, but also provide new data about the manner in which the language of violence is employed. The results suggest that this approach could be a useful addition to the methods more commonly used in this area of stigma research, such as content analysis. ${ }^{45}$ Further, as newspaper readership numbers have declined and social media has increasingly become a source of news information ${ }^{52}$, there will be new challenges to managing the potentially large datasets associated with these new platforms. Corpus linguistics has been used to analyse very large social media datasets ${ }^{53}$, and may well be a useful approach to examine representations of mental health in platforms with a global reach, such as Twitter.

\section{Conclusion.}

Stigma towards people with a diagnosis of mental illness is a global public health issue that impacts negatively on a substantial number of people across a range of life areas. ${ }^{52}$ The press is just one element of this complex process. However, this study suggests that language used in this group of widely read newspapers may contribute to negative views of those diagnosed with schizophrenia, and particularly to a perceived association with violence. The findings suggest that it may be misguided to focus only on encouraging journalists to avoid using pejorative terms such as psycho and schizo. Whilst this is important, the results suggest that newspapers frequently use words which are linguistic signatures of violence. This repeated use of the language of violence, together with the use of the word schizophrenic to reduce the individual to a diagnostic label, is of great concern. Such negative coverage in popular newspapers may well contribute to the processes of stigmatisation towards those who experience psychosis, many of whom have already experienced significant disadvantage, prejudice and discrimination. ${ }^{13}$ 


\section{Conflict of Interest.}

The authors declare no potential conflicts of interest with respect to the research, authorship and/or publication of this article.

\section{Ethical Approval.}

The research is based on publicly available literature and does not require any declaration.

\section{Funding.}

The lead author received funding through (name of University) Research Grants Scheme, which partly supported the study.

\section{References.}

1. Link BG and Phelan JC. Stigma power. Social Science \& Medicine 2014; 103: 24-32.

2. Hipes C, Lucas J, Phelan JC, et al. The stigma of mental illness in the labor market. Social Science Research 2016; 56: 16-25.

3. Byrne T, Bettger JP, Brusilovskiy E, et al. Comparing neighbourhoods of adults with serious mental illness and of the general population: Research implications. Psychiatric Services 2013; 64(8): 782-788.

4. Sharac J, McCrone $P$, Clement $S$ et al. The economic impact of mental health stigma and discrimination: A systematic review. Epidemiologia Psichiatria Sociale 2010; 19(3): 223-232

5. Rüsch N, and Thornicroft G. Does stigma impair prevention of mental disorders? The British Journal of Psychiatry 2014; 204: 249-251.

6. Hamilton S, Pinfold V, Cotney J, et al. Qualitative analysis of mental health service users' reported experiences of discrimination. Acta Psychiatrica Scandinavica 2016; 134(S446): 1422. 
7. Clement S, Schauman O, Graham T, et al. What is the impact of mental health-related stigma on help-seeking? A systematic review of quantitative and qualitative studies. Psychological Medicine 2015; 45(1): 11-27.

8. Brown S, Kim M, Mitchell C, et al. Twenty-five year mortality of a community cohort with schizophrenia. The British Journal of Psychiatry 2010; 196: 116-121.

9. Nordentoft M, Wahlbeck K, Hällgren J, et al. Excess mortality, causes of death and life expectancy in 270,770 patients with recent onset of mental disorders in Denmark, Finland and Sweden. PloS One 2013; 8(1): e55176.

10. Scambler G. Health-related stigma. Sociology of Health \& IIIness 2009; 31(3): 441-455.

11. Cooke A and Harper D. When the Ads Don't Work. Retrieved from: https://blogs.canterbury.ac.uk/discursive/when-the-ads-dont-work/2013

12. Link BG and Phelan JC. Labelling and stigma. In: Aneshensel CS et al (eds) Handbook of the Sociology of Mental Health. 2nd ed. Dordrecht: Springer Science+Business Media, 2013, pp. 522-540.

13. Thornicroft G. Shunned: Discrimination against people with mental illness. Oxford: Oxford University Press, 2006.

14. Corrigan PW and Watson AC. Understanding the impact of stigma on people with mental illness. World Psychiatry 2002; 1(1): 16-20.

15. Link B and Phelan JC. Conceptualizing stigma. Annual Review of Sociology 2001; 27(1): 362-85.

16. McGinty EE, Webster DW and Barry CL. Effects of news media messages about mass shootings on attitudes towards persons with serious mental illness and public support for gun control policies. American Journal of Psychiatry 2013; 170: 494-501.

17. Wilson LC, Ballman AD and Buczek TJ. News content about mass shootings and attitudes toward mental illness. Journalism \& Mass Communication Quarterly 2016; 93(3): 644-658

18. Hoffner CA, Fujioka Y, Cohen EL, et al. Perceived media influence, mental illness, and responses to news coverage of a mass shooting. Psychology of Popular Media Culture 2017; 6(2): 159. 
19.

O’Hara

M.

The

Guardian

Newspaper.,

https://www.theguardian.com/society/2013/sep/18/schizophrenia-mental-healthyoungpeople (18 September, 2013, last accessed 4 June, 2017).

20. Kinderman $\mathrm{P}$ and Cooke A. Mind your language!, https://livrepository.liverpool.ac.uk/3007765/1/mind\%20your\%20language\%20v6.pdf (2018, last accessed 10 June 2018)

21. National Union of Journalists. Responsible reporting on mental health, mental illness and death by suicide. UK, 2015

22. MIND. Virgin Money Giving Mind Media Awards, https://www.mind.org.uk/newscampaigns/mind-media-awards/2017 (last accessed 2 June 2018)

23. Time to Change, https://www.time-to-change.org.uk/newsmedia2018 (last accessed 2 June 2018)

24. Altheide DL and Coyle MJ. Smart on crime: The new language for prisoner release. Crime, Media, Culture 2006; 2(3): 286-303.

25. Thornicroft A, Goulden R, Shefer G, et al. Newspaper coverage of mental illness in England 2008-2011. The British Journal of Psychiatry 2013; 202(s55): s64-s69.

26. Rhydderch D, Krooupa AM, Shefer G, et al. Changes in newspaper coverage of mental illness from 2008 to 2014 in England. Acta Psychiatrica Scandinavica 2016; 134(S446): 45-52.

27. Carpiniello B, Girau R, and Orru MG. Mass-media, violence and mental illness. Evidence from some Italian newspapers. Epidemiology and Psychiatric Sciences 2007; 16(3): 251-255.

28. Dickens G. Portrayal of mental illness and special hospitals in the UK press. British Journal of Nursing 2008; 17(16): 1058-1061.

29. Murphy N, Fatoye F and Wibberley C. The changing face of newspaper representations of the mentally ill. Journal of Mental Health 2013; 22(3): 271-282.

30. Nawkova L, Nawka A, Adamkova T, et al. The picture of mental health/illness in the printed media in three Central European Countries. Journal of Health Communication 2012; 17: $22-40$ 
31. Clement S and Foster N. Newspaper reporting on schizophrenia: A content analysis of five national newspapers at two time points. Schizophrenia Research 2008; 98: 178-183.

32. Flynn S, Gask L and Shaw J. Newspaper reporting of homicide-suicide and mental illness. BJPsych Bull 2015; 39(6): 268-272.

33. National Readership Survey. NRS Sept 16 - Sept 17: United Kingdom. 2017

34. Foster J. Media presentation of the Mental Health Bill and representations of mental health problems. Journal of Community and Applied Social Psychology 2006; 16: 285-300.

35. Jones C and Waller D. Corpus linguistics for grammar: A guide for research. London: Routledge, 2015.

36. Baker P. Using corpora in discourse analysis. London: Bloomsbury Publishing, 2006.

37. Anthony L. AntConc (Version 3.5.6) [Computer Software]. Tokyo, Japan: Waseda University, 2018, http://www.laurenceanthony.net/software

38. Anthony L. A critical look at software tools in corpus linguistics. Linguistic Research 2013; 30(2): 141-161.

39. Mey JL. Corpus linguistics: Some (meta-) pragmatic reflections. Corpus Pragmatics 2017; 1(3): 185-199.

40. Brindle A. A corpus analysis of discursive constructions of the sunflower student movement in the English-language Taiwanese press. Discourse \& Society 2016; 27(1): 3-19

41. Baker P, Gabrielatos $C$ and McEnery T. Discourse analysis and media attitudes: The representation of Islam in the British press. Cambridge: Cambridge University Press, 2013.

42. Koike S, Yamaguchi S, Ojio Y, et al. Effect of name change of schizophrenia on mass media between 1985 and 2013 in Japan: A text data mining analysis. Schizophrenia Bulletin 2015; 42(3): 552-559.

43. University of Lancaster. Log-likelihood and effect size calculator, http://ucrel.lancs.ac.uk/llwizard.html

44. '7/7 stab' lad guilty. The Sun, 7 February 2017, p16 
45. Goodwin J. The horror of stigma: Psychosis and mental health care environments in twenty-first-century horror film (part I). Perspectives in Psychiatric Care 2014; 50(3): 201-209.

46. Bowen ML. Stigma: Content analysis of the representation of people with personality disorder in the UK popular press, 2001-2012. International Journal of Mental Health Nursing 2016; 25(6): 598-605.

47. Quinn T. The tough military Irish American who is trying to save Trump. Daily Mirror, 3 August 2017, p.12.

48. Maddock D. Sublime To Ridiculous. Daily Mirror, 22 November 2017, p.54.

49. Bodker H. Stuart Hall's encoding/decoding model and the circulation of journalism in the digital landscape. Critical Studies in Media Communication 2016; 33(5): 409-423.

51. Pascucci M, Ventriglio A, Stella E et al. Empathy and attitudes towards mental illness among Italian medical students. International Journal of Culture and Mental Health 2017; 10(2): 174.

52. Bowen M and Lovell A. Representations of mental health disorders in print media. British Journal of Mental Health Nursing 2013; 2(4): 198-202.

53. Grieve J, Nin A and Guo D. Mapping lexical innovation on American social media. Journal of English Language 2018; 46(4): 293-319.

53. Bates $L$ and Stickley T. Confronting Goffman: how can mental health nurses effectively challenge stigma? A critical review of the literature. Journal of psychiatric and mental health nursing 2013; 20(7): 569-575. 